\title{
Stability Evaluation of National Reference Standards for Blood Products in Korea
}

\author{
Tae Jun Park ${ }^{1 \dagger}$, Chan Woong Choi ${ }^{1 \dagger}$, Ho Kyung Oh${ }^{2}$, Jae Ok Kim ${ }^{1}$, Byung Kuk Kim', Hyun Kyung Kang', \\ Eun Jeong Kwon', Eun Jeong Gweon', Sang Jin Park', Ho Il Kang' ', Ki Kyung Jung', \\ Sang Mi Park', Ji Hye Kim², Ki Won Han' ${ }^{2}$ and Ja Young Jeong' \\ ${ }^{1}$ Biologics Research Division, National Institute of Food and Drug Safety Evaluation, Cheongju, Korea \\ ${ }^{2}$ Blood Products Division, National Institute of Food and Drug Safety Evaluation, Cheongju, Korea
}

\begin{abstract}
National reference standards (NRSs) for biologics are established through potency estimation by a multicenter joint study of standard materials used in the approval process for national lot release and quality control of vaccines, blood products, and other biologics. In this study, a stability evaluation was conducted to determine whether the potency of NRSs for six blood products was being maintained at a consistent level in Korea. The present study conducted real-time stability tests via in-vivo/in-vitro bioassay on NRSs for blood coagulation factor VIII concentrate (2nd standard), antithrombin concentrate, prekallikrein activator, anti-hepatitis B immunoglobulin, blood coagulation factor IX concentrate, and anti-tetanus human immunoglobulin, as well as a trend analysis using cumulative annual results. The real-time stability test results showed that the mean potency of six NRSs was all within the control limit. In the trend analysis, the potency of NRS for blood coagulation factor VIII concentrate (2nd standard) showed a decreasing trend, while the potency of all other products had been stably maintained. The present study confirmed that the mean potency of NRSs for six blood products had been stably maintained in Korea. The findings of the present study establish a foundation that can ensure the quality of NRSs for biologics in Korea, and it is expected to make a major contribution to the supply of high-quality biologics.
\end{abstract}

Key words: National reference standard, Blood product, Real-time stability test, Trend analysis

\section{INTRODUCTION}

Biologics are substances derived from living organisms, which include recombinant proteins and biological products such as vaccines and blood products with complex compositions and structures. For quality control over these biologics, it is essential to establish standard products that can be used as reference materials for measuring the activities of pharmaceutical agents (1). The National Institute of Food and Drug Safety Evaluation (NIFDS) is in the pro-

Correspondence to: Ja Young Jeong, Biologics Research Division, National Institute of Food and Drug Safety Evaluation, Cheongju 28159, Korea

E-mail: 0jjy@korea.kr

${ }^{\dagger}$ These authors contributed equally to this study.

This is an Open-Access article distributed under the terms of the Creative Commons Attribution Non-Commercial License (http:// creativecommons.org/licenses/by-nc/3.0) which permits unrestricted non-commercial use, distribution, and reproduction in any medium, provided the original work is properly cited. cess of establishing national reference standards (NRSs) for biologics through joint studies based on international standards that follow the guidelines set by the World Health Organization (WHO). This is being conducted for the purposes of approvals for national lot release and quality control and research and development (R\&D) by the manufacturers (2). Since NRSs for biologics are derived from living organisms, they are sensitive to changes in storage temperature and environment; thus, because changes can result in reduced potency, it is necessary to check whether their stability is being maintained (3). Accordingly, the NIFDS conducts regularly scheduled stability tests on NRSs in accordance with the International Conference on Harmonisation $(\mathrm{ICH})$ and $\mathrm{WHO}$ stability testing guidelines $(2,4)$.

Blood products are proteins obtained from the fractioning of human plasma from whole blood, which includes coagulation factors, immunoglobulins, and albumin (5). Blood products may become less active due to changes in temperature, humidity, and $\mathrm{pH}$. Since NRSs for blood products are mostly established on freeze-dried whole blood 
products, the loss of potency may occur over time during storage. Accordingly, for these NRSs to be used as reference materials, it is important to check that a consistent level of potency is being maintained. For this purpose, it is absolutely necessary to conduct real-time stability tests that measure potency via bioassays that consider the characteristics of NRSs for blood products (6).

To achieve product quality of the NRSs used in testing biologics, the present study aimed to conduct a comprehensive stability evaluation of these NRSs via both a trend analysis, using data from the real-time stability tests that were conducted in 2016, and the annual cumulative stability test results from the manufacturers of blood products (e.g., blood coagulation factor VIII concentrate (2nd standard), antithrombin concentrate, prekallikrein activator, antihepatitis B immunoglobulin, blood coagulation factor IX concentrate, and anti-tetanus human immunoglobulin).

\section{MATERIALS AND METHODS}

National reference standards and international standards. The names, code numbers, and specifications of the NRSs and international standards used in the present study are summarized in Table 1 . The NRSs were intended for use with products established and stored by the NIFDS, while the international standards were purchased for use with products established by the National Institute for Biological Standards and Control (NIBSC) of United Kingdom.

Stability test method for Blood coagulation factor VIII concentrate (2nd). The NRS was placed at room temperature (RT) for $30 \mathrm{~min}$, then dissolved in $890 \mu \mathrm{L}$ of deionized water for injection for a final concentration of $10 \mathrm{IU} /$ $\mathrm{mL}$, and kept at RT for an additional $30 \mathrm{~min}$. The diluted NRS was prepared by diluting further to a concentration of $1 \mathrm{IU} / \mathrm{mL}$ with coagulation FVIII-deficient plasma (Siemens, Munich, Germany). The reference material (international standard) was added to $940 \mu \mathrm{L}$ of deionized water for injection for a final concentration of $10 \mathrm{IU} / \mathrm{mL}$ and kept at RT for $30 \mathrm{~min}$. Subsequently, the sample was prepared by diluting to a concentration of $1 \mathrm{IU} / \mathrm{mL}$ with coagulation FVIIIdeficient plasma. The NRS and international standard samples prepared in this manner were further diluted 5-, 10-, 20-, and 40-fold. Next, the potency was measured using a coagulometer (MERLIN Medical, Munich, UK). Using a parallel-line model, the potency of the NRS relative to the international standard was calculated.

Stability test method for Antithrombin concentrate. The NRS was diluted to a concentration of $1 \mathrm{IU} / \mathrm{mL}$ with deionized water, then further diluted 10-, 90-, 120-, and 180 -fold with a buffer solution $(50 \mathrm{mM}$ Tris, $7.5 \mathrm{mM}$ $\mathrm{Na}_{2}$ EDTA-2 $\mathrm{H}_{2} \mathrm{O}, 175 \mathrm{mM} \mathrm{NaCl}, 1 \%$ bovine serum albu$\mathrm{min}$ [BSA], $15 \mathrm{U} / \mathrm{mL}$ heparin). The reference material (international standard) was also prepared by diluting in the same manner as the NRS. The samples were prepared by adding $200 \mu \mathrm{L}$ of each diluted solution to separate tubes and incubated for $1 \mathrm{~min}$ at $37^{\circ} \mathrm{C}$. Next, $200 \mu \mathrm{L}$ of diluted thrombin solution (50 mM Tris, $7.5 \mathrm{mM} \mathrm{Na} 2$ EDTA-2 $\mathrm{H}_{2} \mathrm{O}, 175 \mathrm{mM}$ $\mathrm{NaCl}, 1 \% \mathrm{BSA}$ ) was added to each tube and allowed to react at $37^{\circ} \mathrm{C}$ for $50 \mathrm{sec}$, then the reaction was stopped by adding $500 \mu \mathrm{L}$ of chromogenic substrate solution $(50 \mathrm{mM}$ Tris, $7.5 \mathrm{mM} \mathrm{Na} \mathrm{EDTA}_{2}-\mathrm{H}_{2} \mathrm{O}, 175 \mathrm{mM} \mathrm{NaCl}$ ). Each tube was measured for absorbance at $405 \mathrm{~nm}$, and a parallel-line model was used to calculate the potency of the NRS relative to the international standard.

Stability test method for Prekallikrein activator. Citric acid-sodium chloride and activation buffers were prepared to be used in the serial dilution of the NRS (i.e., 4-, 8-, and 16-fold) and international standard (i.e., 1-, 2-, 4-, and 8fold). The absorbance of the serially diluted NRS and international standard was measured, and a parallel-line model was used to calculate the potency of the NRS relative to the international standard.

Table 1. Details of the national reference standards and international standards

\begin{tabular}{clll}
\hline \hline & & Code & Specification \\
\hline & Blood coagulation factor VIII concentrate (2nd standard) & $09 / 035$ & $8.9 \mathrm{IU} /$ vial \\
National & Antithrombin concentrate & $02 / 008$ & $51.9 \mathrm{IU} /$ vial \\
reference & Prekallikrein activator & $03 / 012$ & $62 \mathrm{IU} / \mathrm{vial}$ \\
standard & Anti-hepatitis B immunoglobulin & $08 / 026$ & $95.45 \mathrm{IU} / \mathrm{vial}$ \\
& Blood coagulation factor IX concentrate & $11 / 037$ & $12 \mathrm{IU} /$ vial \\
& Anti-tetanus human immunoglobulin & $12 / 040$ & $32.74 \mathrm{IU} /$ vial \\
\hline & Blood coagulation factor VIII concentrate (8th international standard) & $07 / 350$ & $8.6 \mathrm{IU} / \mathrm{ampoule}$ \\
& Antithrombin, concentrate, human (3rd international standard) & $06 / 166$ & $4.4 \mathrm{IU} / \mathrm{ampoule}$ \\
International & Prekallikrein activator, human (2nd international standard) & $02 / 168$ & $29 \mathrm{IU} / \mathrm{ampoule}$ \\
standard & Anti-hepatitis B surface antigen immunoglobulin (2nd international standard) & $07 / 164$ & $100 \mathrm{IU} / \mathrm{ampoule}$ \\
& FIX concentrate (4th international standard) & $07 / 182$ & $7.9 \mathrm{IU} / \mathrm{ampoule}$ \\
& Tetanus immunoglobulin, human (1st international standard) & TE-3 & $120 \mathrm{IU} / \mathrm{ampoule}$ \\
\hline
\end{tabular}


Stability test method for Anti-hepatitis B immunoglobulin. To both the NRS and reference material (international standard), $1.0 \mathrm{~mL}$ of sterile water was added and slowly dissolved for at least $20 \mathrm{~min}$. Next, both were diluted to prepare two samples each of 500-, 1,000-, and 2,000-fold dilutions. The potency of the samples was measured using the Roche Elecsys 2010 Immunoassay Analyzer (Roche Diagnostics, IN, USA) and the potency of the NRS relative to the international standard was calculated.

Stability test method for Blood coagulation factor IX concentrate. The NRS and reference material (international standard) were dissolved to a concentration of $1 \mathrm{IU} /$ $\mathrm{mL}$ and then diluted 10-, 20-, 40-, and 80-fold with $9.5 \mathrm{~mL}$ of Dade Owren's Veronal buffer (Siemens) and $0.5 \mathrm{~mL}$ of $20 \%$ human serum albumin, respectively. After adding $100 \mu \mathrm{L}$ of factor IX deficient plasma (Siemens) to a cuvette containing steel balls, $100 \mu \mathrm{L}$ of the diluted NRS and international standard were added. Next, $100 \mu \mathrm{L}$ of Dade Actin Activated Cephaloplastin reagent (Siemens) was added to the solution and kept for $3 \mathrm{~min}$, then $0.0025 \mathrm{M} \mathrm{CaCl}_{2}$ solution (Siemens) was added, and finally, the coagulation reaction was measured. A parallel-line model was used to calculate the potency of the NRS relative to the international standard.

Stability test method for Anti-tetanus human immunoglobulin. Tetanus toxin NRS (MFDS 01/001, 45.5 L+/ vial) was prepared by diluting to $0.5 \mathrm{~L}+/ \mathrm{mL}$ using a gelatin buffer $\left(100 \mathrm{~mL} 0.2 \%(\mathrm{w} / \mathrm{v})\right.$ gelatin, $1.445 \mathrm{~g} \mathrm{Na}_{2} \mathrm{HPO}_{4}, 0.883$ $\mathrm{g} \mathrm{KH}_{2} \mathrm{PO}_{4}, 8.5 \mathrm{~g} \mathrm{NaCl}, 800 \mathrm{~mL}$ distilled water). The test sample (NRS) was diluted to a concentration of $1 \mathrm{IU} / \mathrm{mL}$ using a gelatin buffer. The dilute tetanus toxin and NRS solutions were mixed to various concentrations. The mixed solutions were kept at RT for $1 \mathrm{hr}$ under dark conditions. As with the NRS, the reference material (international standard) was also diluted to a concentration of $1 \mathrm{IU} / \mathrm{mL}$ using a gelatin buffer. The diluted NRS and international standard solutions were mixed to various concentrations with the diluted tetanus toxin solution, then kept at RT for $1 \mathrm{hr}$ under dark conditions. A total of 120 4-week-old, female ICR mice weighing approximately $16 \mathrm{~g}$ were purchased from Samtako (Osan, Korea). The experiments were conducted under the guidelines of the Institutional Animal Care and Use Committee of NIFDS, Korea (1602MFDS-4). Groups were formed with four mice per group. The neutralized mixed solutions, $0.4 \mathrm{~mL}$ each, were administered to the inner thigh of the mice via subcutaneous injection. Subsequently, the animals were observed for $96 \mathrm{hr}$ to detect abnormal reactions and survival, and the findings were recorded. The potency of the NRS relative to the international standard was calculated.

Trend analysis. A regression analysis using auto-regressive error model was performed on the results from stability tests performed from the date of manufacture to 2016 to examine linear trend and fluctuation in potency based on storage period of the NRSs. Moreover, the Durbin-Watson test and test on normality of the residuals were performed to observe autocorrelation. The one-way analysis of variance (ANOVA) or Kruskal-Wallis test was performed to examine differences in potency by year, and if the difference was significant, an adjusted p-value was derived via Bonferroni's method for multiple comparisons.

Statistical analysis. The measured potency of the blood coagulation factor VIII concentrate (2nd), antithrombin concentrate, prekallikrein activator, and blood coagulation factor IX concentrate were calculated using a parallel line model by the European Pharmacopoeia (version 7.0, European Directorate for the Quality of Medicines). For each reference standard, stability test results were calculated as mean, standard deviation, and coefficient of variation and compared to the control limit. A t-test was performed to determine differences between mean potency and labeled potency. SAS software (version 9.3; SAS Institute, Cary, NC, USA) was used for all statistical analyses, with a $p$ value $<0.05$ considered statistically significant.

\section{RESULTS}

Stability evaluation of blood coagulation factor VIII concentrate (2nd). The stability test results on blood coagulation factor VIII concentrate (2nd) showed a potency of $8.69 \pm 0.39 \mathrm{IU} / \mathrm{vial}$, which was within the range of control limit (7.12 10.68 IU/vial). The mean potency was at a 97.64\% level, relative to the labeled potency (8.90 IU/vial), and the t-test of the labeled potency showed no significant difference $(p>0.05)$ (Table 2$)$. The regression analysis using stability test data, accumulated after the establishment of the reference standard, showed a decreasing trend in potency $($ slope $=-0.092, p=0.004$; Fig. $1 \mathrm{~A})$.

Stability evaluation of antithrombin concentrate. The stability test results on antithrombin concentrate showed a potency of $57.43 \pm 3.65 \mathrm{IU} / \mathrm{vial}$, which was within the range of control limit (45.20 58.64 IU/vial). The mean potency was at an $110.66 \%$ level, relative to the labeled potency (51.90 IU/vial), and the t-test of the labeled potency showed no significant difference $(p>0.05)$ (Table 2$)$. Moreover, the regression analysis with 0 months as the reference point showed a stable trend, whereas an analyzing using 12 months as the reference point showed an increasing trend in potency. The regression analysis using stability test data accumulated after the establishment of the reference standard showed a stable trend (slope $=0.290, p=0.054$; Fig. 1B).

Stability evaluation of prekallikrein activator. The stability test results on prekallikrein activator showed a potency of $67.71 \pm 1.94 \mathrm{IU} / \mathrm{vial}$, which was within the range 
Table 2. Results of real-time stability test and details of control limit for each standard

\begin{tabular}{|c|c|c|c|c|c|c|}
\hline \multirow[b]{2}{*}{ Classification } & \multicolumn{6}{|c|}{ National reference standard (IU/vial) } \\
\hline & $\begin{array}{l}\text { Blood coagulation } \\
\text { factor VIII } \\
\text { concentrate }(2 \mathrm{nd})\end{array}$ & $\begin{array}{l}\text { Antithrombin } \\
\text { concentrate }\end{array}$ & $\begin{array}{l}\text { Prekallikrein } \\
\text { activator }\end{array}$ & $\begin{array}{l}\text { Anti-hepatitis B } \\
\text { immunoglobulin }\end{array}$ & $\begin{array}{c}\text { Blood coagulation } \\
\text { factor IX } \\
\text { concentrate }\end{array}$ & $\begin{array}{c}\text { Anti-tetanus } \\
\text { human } \\
\text { immunoglobulin }\end{array}$ \\
\hline Result (Mean \pm SD) & $8.69 \pm 0.39^{\mathrm{a}}$ & $57.43 \pm 3.65^{\mathrm{b}}$ & $67.71 \pm 1.94^{\mathrm{b}}$ & $103.08 \pm 2.89^{\mathrm{b}}$ & $12.76 \pm 0.32^{\mathrm{b}}$ & $32.74 \pm 0.00^{\mathrm{b}}$ \\
\hline Relative potency (\%) & 97.64 & 110.66 & 109.21 & 107.99 & 106.33 & 100.00 \\
\hline Labeled potency & 8.90 & 51.90 & 62.00 & 95.45 & 12.00 & 32.74 \\
\hline Control limit & $\begin{array}{c}80 \%< \\
\text { Relative potency } \\
<120 \%\end{array}$ & $\begin{array}{c}\text { Mean } \\
\text { potency } \pm 3 \sigma^{c}\end{array}$ & $\begin{array}{c}\text { Mean } \\
\text { potency } \pm 3 \sigma^{c}\end{array}$ & $\begin{array}{c}\text { Mean } \\
\text { potency } \pm 3 \sigma^{c}\end{array}$ & $\begin{array}{c}\text { Mean } \\
\text { potency } \pm 3 \sigma^{c}\end{array}$ & $\begin{array}{c}\text { Mean } \\
\text { potency } \pm 3 \sigma^{c}\end{array}$ \\
\hline Upper control limit & 10.68 & 58.64 & 67.74 & 111.58 & 14.30 & 34.45 \\
\hline Lower control limit & 7.12 & 45.20 & 55.86 & 79.32 & 9.68 & 31.03 \\
\hline$p$-Value for $t$-test ${ }^{\mathrm{d}}$ & 0.254 & 0.119 & 0.036 & 0.045 & 0.055 & - \\
\hline
\end{tabular}

${ }^{\mathrm{a}} \mathrm{Six}$ repeated experiments.

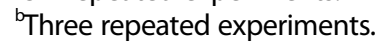

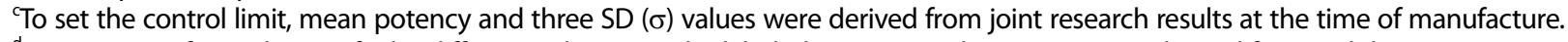

${ }^{d} t$-test was performed to verify the differences between the labeled potency and mean potency derived from stability testing.

of control limit (55.86 67.74 IU/vial). The mean potency was at a $109.21 \%$ level, relative to the labeled potency $(62.00 \mathrm{IU} / \mathrm{vial})$, and the t-test of the labeled potency showed a significant difference $(p<0.05)$ (Table 2). Regression analysis using the stability test data accumulated after the establishment of the reference standard showed a stable trend (slope $=0.100, p=0.499$; Fig. 1C).

Stability evaluation of anti-hepatitis B immunoglobulin. The stability test results on anti-hepatitis B immunoglobulin showed a potency of $103.08 \pm 2.89 \mathrm{IU} / \mathrm{vial}$, which was within the range of control limit (79.32 111.58 IU/vial). The mean potency was at a $107.99 \%$ level, relative to the labeled potency ( $95.45 \mathrm{IU} / \mathrm{vial})$, and the t-test of the labeled potency showed a significant difference $(p>0.05)$ (Table 2). The regression analysis using stability test data accumulated after the establishment of the reference standard showed a stable trend (slope $=-0.085, p=0.876$; Fig. 1D).

Stability evaluation of blood coagulation factor IX concentrate. The stability test results on blood coagulation factor IX concentrate showed a potency of $12.76 \pm 0.32 \mathrm{IU} /$ vial, which was within the range of control limit (9.68 14.30 $\mathrm{IU} / \mathrm{vial})$. The mean potency was at a $106.33 \%$ level, relative to the labeled potency $(12.00 \mathrm{IU} / \mathrm{vial})$, and the t-test of the labeled potency showed no significant difference $(p>0.05)$ (Table 2). The regression analysis using stability test data accumulated after the establishment of the reference standard showed a stable trend (slope $=-0.173, p=0.070$; Fig. 1E).

Stability evaluation of anti-tetanus human immunoglobulin. The stability test results on anti-tetanus human immunoglobulin showed a potency of $32.74 \pm 0.00 \mathrm{IU} / \mathrm{vial}$, which was within the range of control limit (31.03 34.45 $\mathrm{IU} /$ vial). The mean potency was found to be the same as the labeled potency ( $32.74 \mathrm{IU} / \mathrm{vial}$; Table 2). The regression analysis using stability test data accumulated after the establishment of the reference standard showed a stable trend (slope $=-0.157, p=0.426$; Fig. 1F).

\section{DISCUSSION}

NRSs for biologics are reference materials used in the approval process for national lot release, quality control, and $\mathrm{R} \& \mathrm{D}$, which are being distributed to pharmaceutical companies and research institutions. Currently, in Korea, a total of 33 NRSs for biologics have been established by the NIFDS, including 20 vaccines, 9 blood products, and 4 recombinant protein products. The quality of these NRSs is ensured through real-time stability tests and statistical analyses. The ICH and WHO stability testing guidelines recommend that, as a standard practice, real-time stability testing on reference standards should be performed at the time of manufacture and 3, 6, 9, 12, 18, and 24 months after the manufacture date, as well as annual testing thereafter (7). By using both the stability test results of NRSs, obtained for manageability assessment through comparisons with control limits and trend analysis using regression analysis, the changing trend in potency according to storage time can be predicted. Scientific openness and transparency are important elements in the management of biologic reference standards, and national control laboratories in charge of stability evaluations must be able to provide such scientific data to their stakeholders through peer-reviewed publication (8).

The present study conducted stability testing of NRSs for six blood products using various testing methods including 
(A)

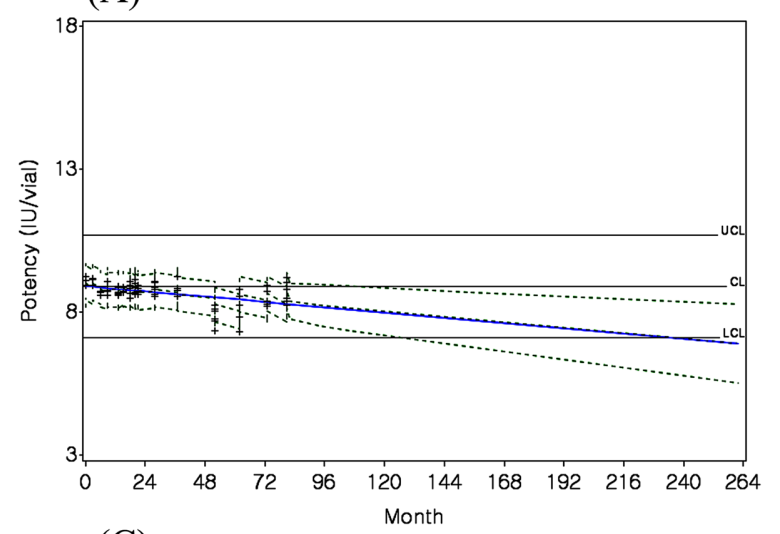

(C)

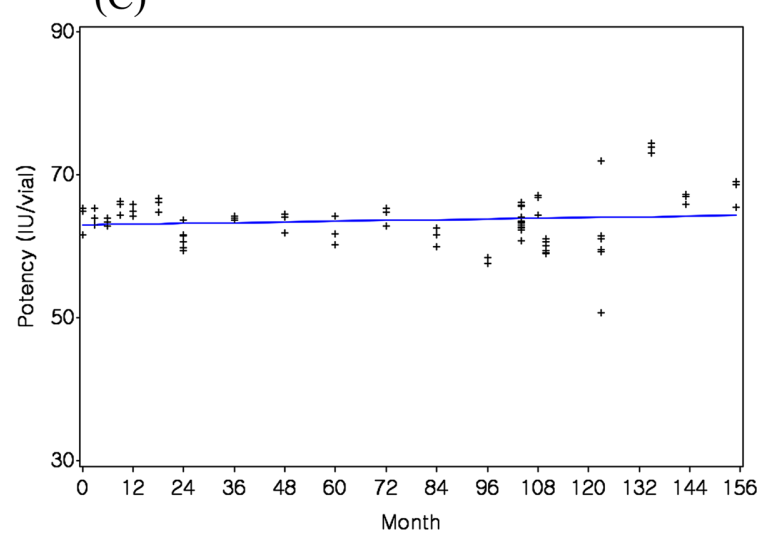

(E)

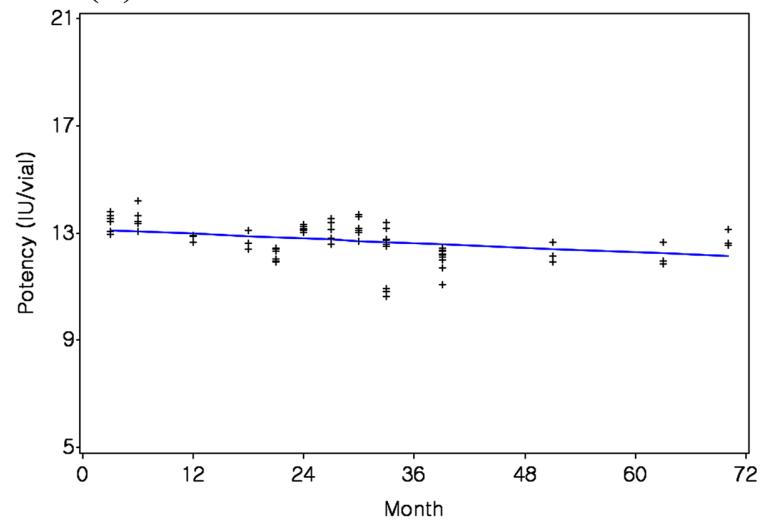

(B)

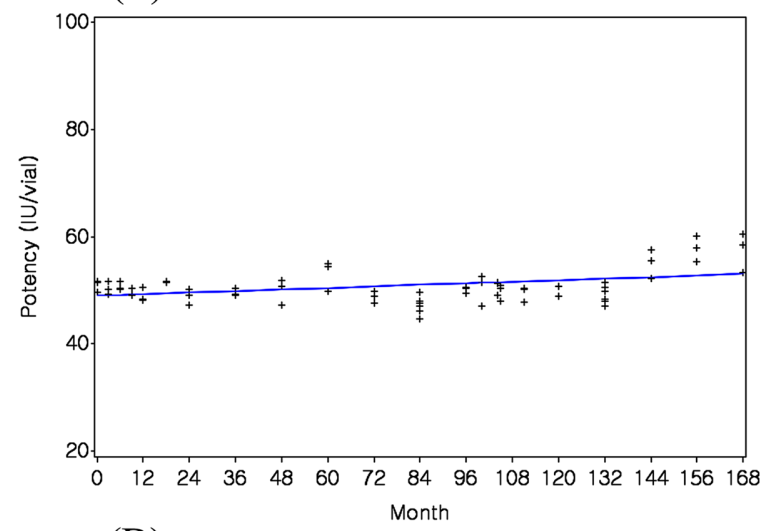

(D)

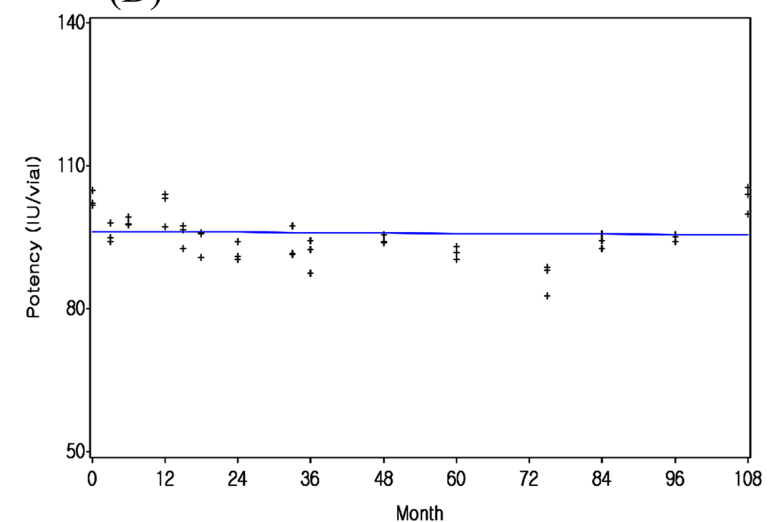

(F)

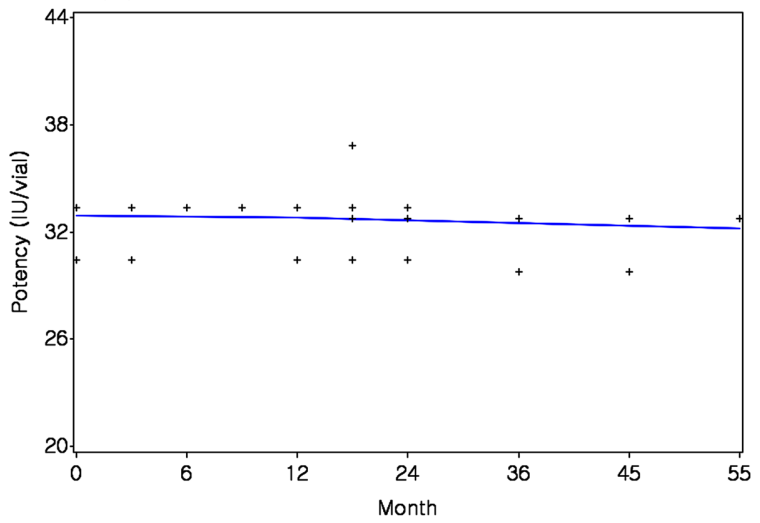

Fig. 1. Trend analysis of national reference standards. Results of regression analysis using auto-regressive error model on stability test data accumulated after establishment. (A) Blood coagulation factor VIII concentrate (2nd), (B) Antithrombin concentrate, (C) Prekallikrein activator, (D) Anti-hepatitis B immunoglobulin, (E) Blood coagulation factor IX concentrate, and (F) Anti-tetanus human immunoglobulin.

chromogenic substrate assay of measuring the potency of protein enzymes involved in blood coagulation, such as thrombin and prothrombin (9); blood coagulation time measurement for measuring the potency of blood coagulation factors (10); and antigen/antibody assay and electrochemiluminescent immunoassay for measuring the potency of globulin (11). The test results showed significant differences in the mean potency of prekallikrein activator and anti-hep- atitis B immunoglobulin, as compared to their respective labeled potency. However, since the mean potency of all six NRSs appeared within their respective control limit, it was determined that they were stably maintained. Moreover, a trend analysis was conducted at the time of establishment and 12 months after the establishment as the reference points in examining the trend in the stability of NRSs. The reason for the selection of 12 months as the reference point was to 
(A)

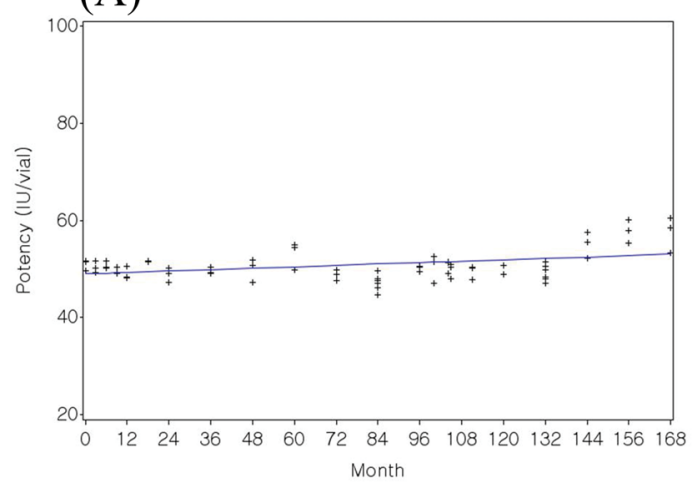

(B)

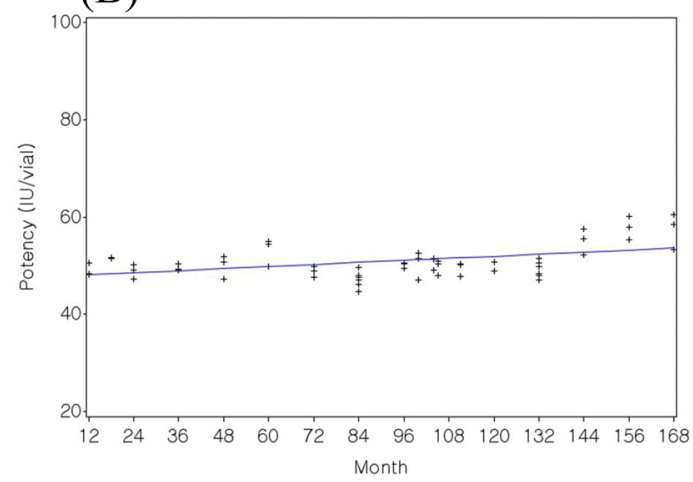

Fig. 2. Trend analysis of antithrombin concentrate. (A) Results of regression analysis through stability test data accumulated after establishment. (B) Results of regression analysis on stability test data for 12-month periods, which were collected since the time the stabilization process had been completed.

set a post-manufacturing stabilization period that was based on the nature of biologics. The results of the trend analysis indicated that the potency of antithrombin concentrate, antihepatitis B immunoglobulin, blood coagulation factor IX concentrate, and anti-tetanus human immunoglobulin all showed a stable trend. Although the potency of prekallikrein activator also showed a stable trend, its potency at 135 months $(73.78 \pm 0.70 \mathrm{IU} /$ vial $)$ exceeded the upper limit of control (data not shown). However, subsequent tests at 143 and 155 months showed a potency of $66.73 \pm 0.73$ and $67.71 \pm 1.94 \mathrm{IU} / \mathrm{vial}$, respectively, which was within the control limit. On the other hand, the potency of blood coagulation factor VIII concentrate (2nd) showed a decreasing trend. According to the trend curve, it appears potency may fall below the lower limit of control after 240 months. Interestingly, antithrombin concentrate showed a stable trend in potency when 0 months was used as the reference point, but an increasing trend when 12 months was used as the reference point (Fig. 2). It is believed that this does not reflect an actual increase in potency, but rather, because the potency at the most recent two measurement points (156 and 168 months) was close to the upper limit of control $(57.80 \pm$ 2.39 and $57.43 \pm 3.65 \mathrm{IU} / \mathrm{vial}$, respectively). The $\mathrm{pH}$ and humidity of $6 \mathrm{NRSs}$ for blood products were measured along with the potency based on the stability testing cycle, and the results were shown maintained within the criteria for each of the NRSs (data not shown).

Through the findings of the present study, it was confirmed that the potency of NRSs for six blood products was being stably maintained. Timely supply of blood product is very important and we have experienced a delayed supply of international standard, establishing NRSs is one of the highly demanded responsibilities of national control laboratory (12). Real-time stability tests and trend analyses on the NRSs should be conducted regularly to verify the quality of these reference standards, which is essential for ensuring the quality of biologics. The stability evaluation results in this study could be used as evidential data for establishing stable management measures for NRSs, and ultimately, the findings are expected to make a significant contribution to the supply of high-quality biologics.

\section{CONFLICT OF INTEREST}

The authors have disclosed no conflicts of interest.

\section{ACKNOWLEDGMENTS}

This study was supported by a grant from the scientific research program (16171MFDS198) at NIFDS, MFDS.

Received April 13, 2017; Revised June 8, 2017; Accepted June 12, 2017

\section{REFERENCES}

1. Knezevic, I. (2009) Stability evaluation of vaccines: WHO approach. Biologicals, 37, 357-359.

2. World Health Organization (2011) WHO manual for the establishment of national and other secondary standards of vaccines (Ordering code: WHO/IVB/11.03), WHO, Geneva.

3. World Health Organization (1992) Annex 2: Guidelines for national authorities on quality assurance for biological products (WHO Technical Report Series, No. 822), WHO.

4. ICH (2003) Stability testing of new drug substances and products, Q1A(R2), step 4, ICH.

5. Epstein, J.S. (2012) Best practices in regulation of blood and blood products. Biologicals, 40, 200-204.

6. Raut, S. and Hubbard, A.R. (2010) International reference standards in coagulation. Biologicals, 38, 423-429.

7. World Health Organization, Regional Office for the Eastern Mediterranean (2006) Draft regional guidelines on stability testing of active substances and pharmaceutical products (Gov't Doc \#: EM/RC53/R.12), WHO.

8. NIBSC (2012) Guidance document for the production, characterization and value assignment of biological reference 
materials, Materials document serial, NIBSC.

9. Kang, H.N., Kim, S.N., Lee, S.H. and Hong, S.H. (2004) A collaborative study to establish a Korean Standard for factor VIII: C concentrate. Thromb. Res., 113, 261-267.

10. Kang, H.N., Lee, S.H., Kim, S.N., Hong, C.M., Lee, S.H. and Hong, S.H. (2006) A collaborative study to establish a Korea national biological standard for antithrombin concentrate. Thromb. Res., 117, 591-596.
11. Kim, H., Shin, A.R., Chung, H.H., Kim, M.K., Lee, J.S., Shim, J.J. and Kim, B.H. (2013) Recent trends in hepatitis B virus infection in the general Korean population. Korean $J$. Intern. Med., 28, 413-419.

12. Kang, H., Roh, H.S., Song, H., Lee, K., Chung, S.T., Ban, S.J., Mo, I.P., An, B.S. and Ahn, C.Y. (2016) Evaluation of haemagglutinin content by RP-HPLC to generate pandemic influenza vaccine. Toxicol. Res., 32, 269-274. 